\title{
An intraventricular thrombus of unknown origin
}

\section{Un trombo intraventricular de origen desconocido}

Ramón Maruri-Sánchez¹, Guillermo Diego-Nietoº , Manuel E. Monguió-Santín², Corazón M. Calle-Valdă Guillermo Reyes-Copa ${ }^{2}$, and Fernando Alfonso ${ }^{1 *}$

${ }^{1}$ Department of Cardiology; ${ }^{2}$ Department of Cardiac Surgery, Hospital Universitario de La Princesa, Madrid, Spain

A thirty-eight-year-old male, hypertensive, dyslipidaemic and smoker, with no cardiovascular treatment, had an episode of left lower limb deep venous thrombosis 2 years back, which was resolved with subcutaneous heparin and without further study. Currently, he had been admitted for a stroke in the territory of the right middle cerebral artery treated with thrombectomy, without clinical sequelae. There were no signs or symptoms of heart disease. Monitoring at admission did not detect arrhythmias. An echocardiogram showed a fusiform image within the left ventricle, with a length of $4 \mathrm{~cm}$ and an area of $4.2 \mathrm{~cm}^{2}$, anchored to the apex, with chaotic movement inside the ventricular cavity. The left ventricle had normal size, with normal global and segmental systolic function. The described image was consistent with an intracavitary thrombus or a tumour mass (Fig. 1A). Given the characteristics of the mass (large, mobile, and pediculated), surgical intervention was decided. By means of median sternotomy and under cardiopulmonary bypass, the left ventricle was accessed through the left atrium, and excision of the mass was carried out. It had a size of $4 \mathrm{~cm} \times 2 \mathrm{~cm}$ and an encapsulated aspect, with a lumpy yellowish content (Fig. 2). It was anchored to the muscular endocardium. Anatomopathological diagnosis indicated a blood thrombus with the presence of focal calcification.
After surgery, the patient evolved favorably $A$ post-operative echocardiogram showed a left ventricle with preserved function and apex without remains of the excised tumour mass (Fig. 1B). In the outpatient setting, a thrombophilia study was carried out, which included, among others, protein $\mathrm{C}$, protein $\mathrm{S}$, antithrombin III, prothrombin gene mutation, factor $\mathrm{V}$ Leiden, anticardiolipin antibodies, anti-beta-2 glycoprotein, and lupus anticoagulant. All results were normal. The-patient has not experienced new clinical events. A control cardiac magnetic resonance imaging showed a left $\bar{v}$ entricle of normal size and function, without evidence of intracavitary thrombus.

\section{Discussion}

The formation of intraventricular thrombi is uswally associated with myocardial contractility changes in the context of an extensive myocardial infarction. These lesions have also been described in other pathologies that can cause alterations of the myocardial function, such as myocarditis or takotsubo cardiomyopathy. Rare cases have been published where the formation of intracavitary thrombi occurred in ventricles of normalsize and function ${ }^{1,2}$. In some of them, other causes were identified that might explain the formation of thrombi,

\section{Correspondence:}

*Fernando Alfonso

Servicio de Cardiología

Hospital Universitario de La Princesa

Diego de León, 62

Date of reception: 15-10-2018

28006 Madrid, España

E-mail: falf@ hotmail.com

2604-7063/@ 2019 Instituto Nacional de Cardiología Ignacio Chávez. Published by Permanyer. This is an open access article under the CC BYlicense (http://creativecommons.org/licenses/by-nc-nd/4.0/).
Available online: 06-05-2019 Arch Cardiol Mex (Eng). 2019;89(3):267-269 www.archivoscardiologia.com

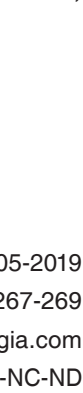



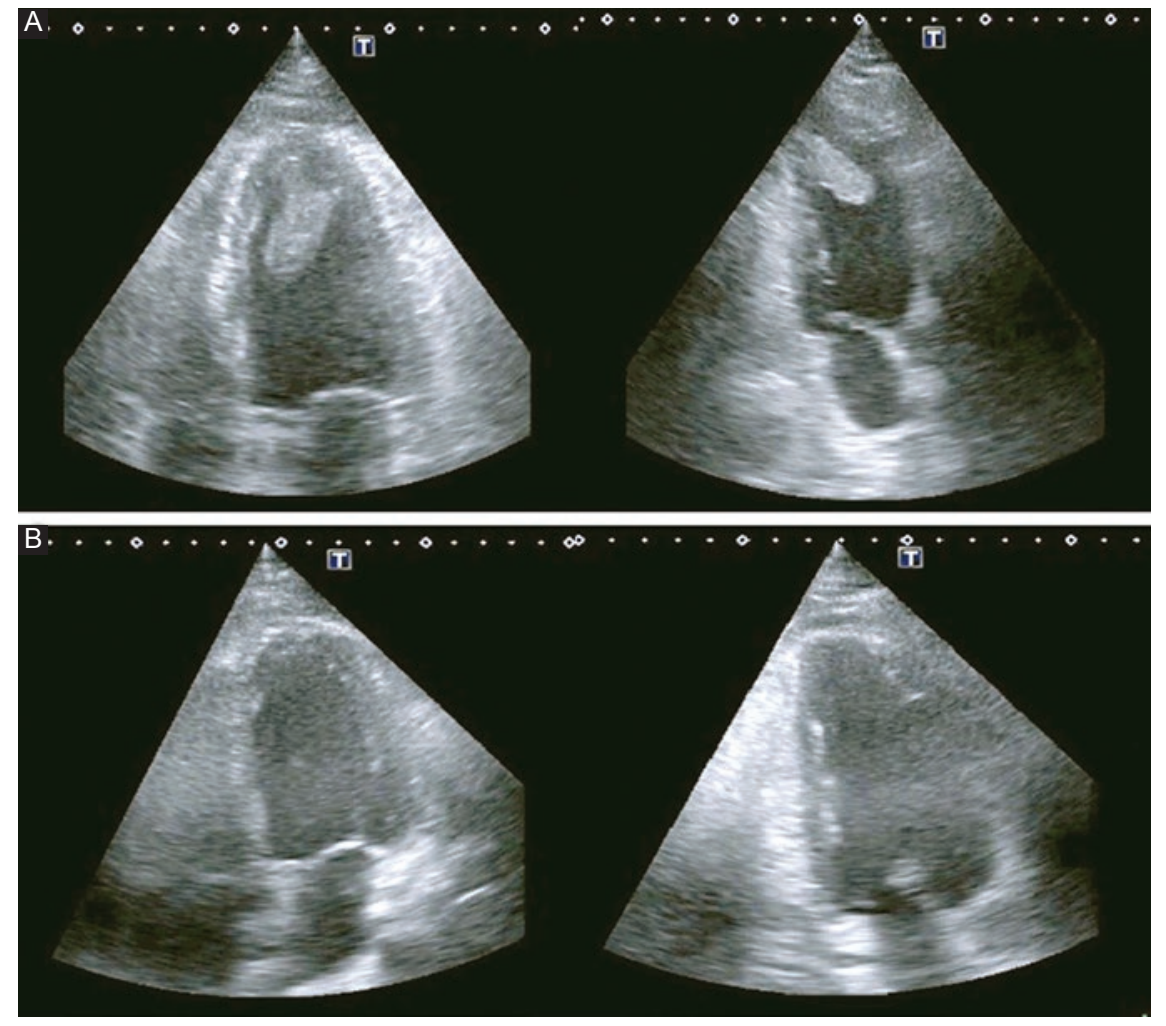

Figure 1. Echocardiogram. A: four- and two-chamber projections showing the thrombus anchored to the left ventricle apex. B: four- and two-chamber projections showing the left ventricle free of thrombus after the intervention.

such as coagulation disorders ${ }^{3}$ or inflammatory diseases (Behçet disease or lupus erythematosus). To date, we have not found documented cases of thrombi inside normal ventricles where, despite exhaustive examination, no cause could be found that could explain their formation, as occurred in our patient.

As for therapeutic management, clinical practice guidelines and specialized literature exclusively recommend anticoagulation in patients with intraventricular thrombi, regardless of their characteristics. Protrusion and mobility are the most important predictors of intracavitary thrombi embolization. Some cases have been described where, in the presence of thrombi with high embolic risk, surgical resection was preferred versus management exclusively with anticoagulation ${ }^{4-6}$. The results were good and the patients did not experience subsequent cardioembolic episodes. Although surgery significantly reduces thrombus emboligenic risk versus anticoagulation, it entails myocardial damage due to the access through ventriculotomy. Therefore, new access routes to intraventricular thrombi that reduce myocardial damage have been proposed, such as transaortic access and left atrial access, which was the chosen route in our case. This access

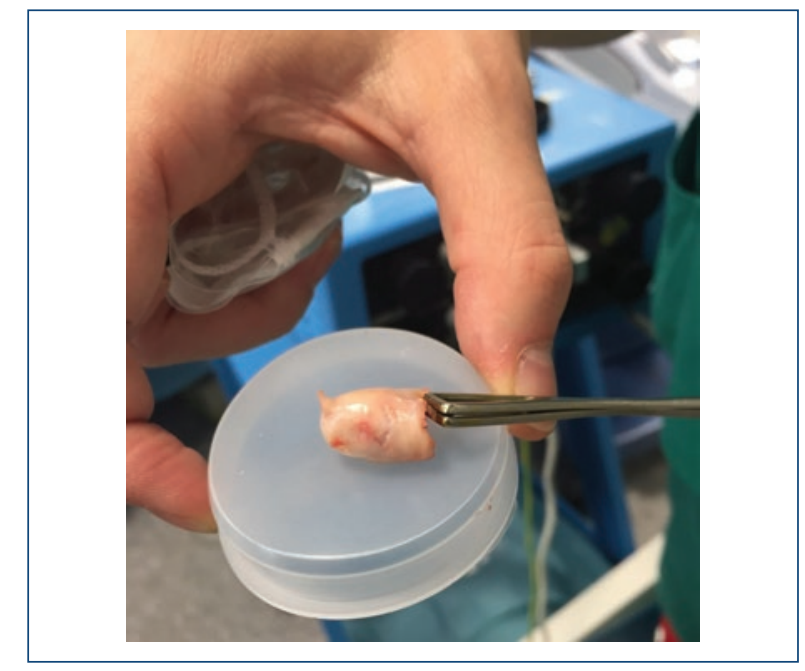

Figure 2. Surgical specimen after resection.

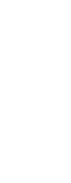

allowed rapid identification and removal of the thrombus through the mitral valve without causing significant myocardial harm. Our patient had a good clinical evolution without new events during follow-up. Therefore, surgical 
resection of high embolic risk intraventricular thrombi seems quite reasonable versus exclusive anticoagulation. However, this is something that clinical practice guidelines and specialized literature still do not contemplate.

\section{Conflicts of interest}

The authors declare that they have no conflicts of interest.

\section{Funding}

The authors declare that they have not received any funding in relation to this manuscript.

\section{Ethical disclosures}

Protection of people and animal subjects. The authors declare that no experiments were performed on humans or animals for this study.
Confidentiality of data. The authors declare that they have followed the protocols of their work center on the publication of patient data.

Right to privacy and informed consent. The thors have obtained written informed consent of the patients and/or subjects mentioned in the article. The corresponding author is in possession of this document.

\section{References}

1. Verma AK, Alam M, Rosman HS, Brymer J, Keith F. Systemic embolization from thrombus in normal left ventricles. Chest. 1988;93(2):441-2.

2. Kawamoto J, Ishibashi K, Shibukawa T, Izutani H. Left ventricular thrombus with a normal heart. Gen Thorac Cardiovasc Surg. 2007;55(8):322-4.

3. Cianciulli TF, Saccheri MC, Lax JA, Neme RO, Sevillano JF, Maiori ME, et al. Left ventricular thrombus mimicking primary cardiac tumor in a patient with primary antiphospholipid syndrome and recurrent systemic embolism. Cardiol J. 2009;16(6):560-3.

4. John RM, Sturridge MF, Swanton RH. Pedunculated left ventricular thrombus - report of two cases. Postgrad Med J. 1991;67(791):843-5.

5. Cousin E, Scholfield M, Faber C, Caldeira C, Guglin M. Treatment options for patients with mobile left ventricular thrombus and ventricular dysfunction: a case series. Heart Lung Vessel. 2014;6(2):88-91.

6. Tanaka D, Unai S, Diehl JT, Hirose H. Surgical removal of a large mobile left ventricular thrombus via left atriotomy. World J Clin Cases $\$ 2014$; 2(2):32-5 